\title{
DA FILANTROPIA AO INVESTIMENTO SOCIALMENTE RESPONSÁVEL: novas distinções ${ }^{1}$
}

\author{
Marina de Souza Sartore*
}

\begin{abstract}
As transformações no mundo organizacional e das finanças geram oposições as quais definem as posições dos atores atuantes no espaço social, que denomino de "Espaço das Práticas Sociais dos Empresários”. Meu principal argumento é o de que essas transformações recentes ficam mais evidentes a partir da incorporação das ideias da Sustentabilidade Empresarial (SE) por atores ligados ao campo das finanças, a qual ocorre a partir da criação do Índice de Sustentabilidade Empresarial (ISE) na Bolsa de Valores do Estado de São Paulo em 2005. Concluo este artigo apresentando a cartografia desse espaço social formado a partir de polarizações entre a filantropia, o velho, o tradicional, o local versus o meio ambiente, o novo, o moderno e o global ou ainda, de um lado, as finanças e o investimento socialmente responsável versus a responsabilidade social empresarial e a sustentabilidade empresarial.

PALAVRAS-CHAVE: Espaço social. Sustentabilidade empresarial. Responsabilidade social empresarial. Investimento socialmente responsável. Sociologia econômica.
\end{abstract}

\section{INTRODUÇÃO}

As práticas de Responsabilidade Social das Empresas (RSE) ganham ênfase no espaço organizacional a partir da década de noventa, principalmente pela atuação de atores sociais associados ao Instituto Ethos de Responsabilidade Social das Empresas, criado em 1998. No entanto, a ideia de que o empresário possui um papel social a ser desempenhado em prol da sociedade antecede os anos noventa e vem passando por transformações, criando novas formas de atuação no mundo dos negócios. Essas transformações, dentre as quais situo a RSE, geram oposições as quais definem as posições dos atores sociais atuantes na emergência do espaço social, o qual denomino de Espaço das Práticas Sociais dos Empresários.

* Doutora em Ciências Sociais. Professora da Universidade Federal de Goiás (UFG).

Campus II, Samambaia. Caixa Postal: 131. Cep: 74001970 - Goiânia - Goiás. marina.ufg@gmail.com

${ }^{1}$ Agradeço à CAPES pelo financiamento da tese de doutorado da qual este artigo é o resultado. Agradeço ao orientador dessa tese, Roberto Grün, aos colegas do Núcleo de Estudos de Sociologia Econômica e das Finanças (NESEFI), e à banca examinadora de minha defesa pelos valiosos comentários.
O espaço social a que faço referência é o conceito utilizado por Pierre Bourdieu, o qual é "construído sobre a base de princípios de diferenciação ou de distribuição, constituídos pelo conjunto de propriedades que agem no universo social considerado" (Bourdieu, 1984, p. 3).

Para esboçar os contornos desse espaço social, a pesquisa realizada, da qual este artigo é o resultado, recupera os agentes envolvidos com o tema das práticas sociais dos empresários, focando principalmente as suas transformações recentes. O meu principal argumento é de que essas distinções recentes ficam mais evidentes a partir da incorporação das ideias da Sustentabilidade Empresarial (SE) ocorrida a partir da criação do Índice de Sustentabilidade Empresarial (ISE) na Bolsa de Valores do Estado de São Paulo, em 2005. Ao desenhar esse espaço, busco contribuir para a discussão sobre a especificidade do modelo de capitalismo que está se formando no Brasil, no qual, segundo Grün (2009, p. 159), “o campo financeiro adquiriu centralidade e sua dinâmica interna é decisiva para a conformação dos demais setores da economia". 
Para a recuperação dos atores sociais, utilizei a pesquisa documental e a busca em minibiografias publicadas em páginas eletrônicas. Para uma melhor compreensão analítica, dividi este artigo em três momentos distintos, porém interdependentes. $\mathrm{O}$ primeiro momento remete à ramificação da filantropia empresarial para as práticas da Responsabilidade Social das Empresas (RSE). O segundo consiste na distinção entre a Responsabilidade Social das Empresas (SER) e a Sustentabilidade Empresarial (SE). No terceiro, a SE é incorporada pelo setor financeiro, desdobrando-se em Finanças Sustentáveis (FS), as quais abrigam as práticas de Investimento Socialmente Responsável (ISR).

Concluo este artigo apresentando esse espaço social e mencionando o potencial analítico da sociologia das gerações para explicar suas distinções.

\section{FILANTROPIA EMPRESARIAL VERSUSRES- PONSABILIDADE SOCIAL DAS EMPRESAS}

O surgimento da filantropia empresarial no Brasil tem uma pré-história nos anos 60, com a criação da Associação Cristã dos Dirigentes de Empresas do Brasil, criada para chamar a atenção para o papel social dos empresários (Cappellin; Giuliani, 2004).

No entanto, Beghin (2005) situa as origens da RSE nos anos 80, quando o Brasil vivenciava o fim do regime militar, o advento da globalização econômica e financeira, a novidade gerencial da reestruturação do trabalho e o encolhimento do papel social do Estado. Essas mudanças criaram um cenário brasileiro paradoxal nos moldes descritos por Castel (1998) para a França, e Guilhot (2006) para os Estados Unidos: o aumento da pobreza da população e a acumulação de riquezas pelas empresas levaram ao surgimento de ações sociais por parte dos empresários.

Beghin (2005) separa a criação das práticas sociais dos empresários em dois momentos distintos: o primeiro pertence à década de 80 , quando a preocupação era a de erradicar a pobreza atra- vés da filantropia empresarial, impulsionada por um sentimento religioso através do qual a ajuda é dada por esmolas e doações por parte dos empresários. Esse tipo de filantropia empresarial é questionado na década de 90 por instituições que irão implantar a neofilantropia empresarial (Beghin, 2005), a qual propõe gerir continuamente a pobreza e não mais erradicá-la.

Como porta-voz da filantropia empresarial aparece a Fundação Instituto de Desenvolvimento Empresarial e Social (FIDES), criada em 1986. Essa fundação foi precedida pelo Instituto de Desenvolvimento Empresarial, o qual tem suas origens baseadas em princípios religiosos (Agüero, 2005).

A FIDES foi fundada e institucionalizada por empresários e executivos de São Paulo, Rio de Janeiro, Bahia e Rio Grande do Sul (FIDES, 2010). O conselho curador do ano de 2010 é formado por Alberto Augusto Perazzo, Alberto Luiz Gonçalves Soares, Álvaro Conde Lemos Filho, Jan Wiegerinck, Nelson Gomes Teixeira (que chegou a ser presidente da Associação dos Dirigentes Cristãos no Brasil) e Peter Nadas (FIDES, 2010b). Ao analisar a minibiografia desses agentes, é possível verificar que, em sua maioria, eles pertencem à geração de empresários tradicionais da década de sessenta e setenta, orientados por uma ação social católico-cristã, atuantes como conselheiros em Organizações Não Governamentais (ONGs) e militantes a favor do ensino da Ética nos cursos de administração e negócios.

O Instituto Brasileiro de Análises Sociais e Econômicas (IBASE) foi criado em 1980 com o "caráter suprapartidário e suprarreligioso, dedicado a democratizar a informação sobre as realidades econômicas, políticas e sociais no Brasil” (IBASE, 2010). O IBASE possui uma característica intermediária, pois, ao mesmo tempo em que foi fundado por um líder de orientação cristã católica, nascido em 1935 - o que o aproxima da filantropia empresarial -, esse mesmo líder passou a cobrar uma atuação social mais sistemática das empresas, que seria monitorada pela publicação do Balanço Social - atitude que o aproxima das bases da neofilantropia empresarial. 
Como porta-vozes da neofilantropia empresarial estão o Grupo de Instituições, Fundações e Empresas (GIFE), o Pensamento Nacional das Bases Empresariais (PNBE) e o Instituto Ethos.

O GIFE foi formado por 25 representantes de grupos privados nacionais (Carrion; Garay, 2000) e tem como principal contribuição a implementação da ideia de investimento social privado. Segundo o GIFE (2009), o investimento social privado consiste no "repasse voluntário de recursos privados de forma planejada, monitorada e sistemática para projetos sociais, ambientais e culturais de interesse público".

Os profissionais que participaram na fundação do GIFE têm em comum a atuação profissional em empresas de grande porte, o que os levou a assumir a direção das fundações sociais dessas empresas. Trata-se de um grupo de executivos atuantes na década de 80 e que incorporaram a ideia de atuação social mais sistemática pelo empresariado nacional.

Estamos na década de 80, quando, segundo Diniz e Boschi (1993), a crise política opunha empresários simpáticos à ideia de intervenção estatal na economia versus aqueles crédulos em uma ideologia neoliberal. Essa dualidade culminou na formação de novos grupos de representação de interesses, dentre os quais o Instituto de Estudos para o Desenvolvimento Industrial (IEDI) e o Pensamento Nacional das Bases Empresariais (PNBE).

O PNBE foi criado em 1987, a partir de uma audiência pública convocada por, naquele momento, jovens lideranças, com o intuito de debater as propostas dos empresários submetidas à Assembleia Constituinte, assim como resolver a crise de representatividade do empresariado nesse período (Bianchi, 2001). Segundo Assis (2008), o grupo que formou o PNBE era constituído de empresários que participavam da Federação de Indústrias do Estado de São Paulo (FIESP), mas que, no entanto, criticavam-na, pois acreditavam que "os empresários queriam mais independência e consideravam a FIESP muito ligada ao governo e em constante posição de confronto com os sindicatos." Em sua visão, o PNBE procurava moderni- zar as relações entre os empresários e a sociedade (Agüero, 2005) e, inicialmente, pregava uma participação conjunta do Estado e do empresariado para a construção de uma sociedade democrática brasileira, assim como de uma maior participação dos trabalhadores (Bianchi, 2001).

Oded Grajew e Emerson Kapaz são os principais executivos que lideraram a formação do PNBE. Engenheiros (o primeiro formado pela Universidade de São Paulo e o segundo formado pelo Instituto Mackenzie) e com pós-graduação na Fundação Getúlio Vargas, ambos trabalhavam em médias empresas com atuação na fabricação de jogos e brinquedos (o primeiro fundou a Grow - jogos e brinquedos - em 1972, enquanto o segundo assumiu a Elka Plásticos, empresa familiar que havia sido fundada por seu pai).

A década de 90 representou um aumento do setor de serviços no Brasil, mudando a composição do PNBE, que passou a ser majoritariamente composto por pequenos e médios empresários atuantes principalmente no setor de serviços, os quais defendiam uma participação dessa parcela do empresariado para a constituição da democracia no Brasil (Bianchi, 2001).

Segundo Agüero (2005), a criação da Fundação Abrinq pelos direitos da criança e do adolescente foi fundamental para o desenvolvimento do conceito de RSE no Brasil. A fundação foi criada por membros associados ao PNBE, com o intuito de defender os direitos da criança e do adolescente, principalmente no que concerne ao trabalho infantil. Não surpreende o fato de que o grupo tenha fundado uma organização não governamental na busca de soluções para problemas sociais, visto que o PNBE acreditava que o empresariado poderia "dar conta, com êxito, das funções sociais do Estado" (Membro de PNBE entrevistado por Diniz e Boschi, 1993, p. 101).

Seguindo a reconstituição de Agüero (2005), um pequeno grupo da Abrinq passou a estudar como a RSE era desenvolvida nos Estados Unidos e na Europa. Essas pesquisas levaram-no a entrar em contato com o Business for Social Responsibility (BSR), culminando na fundação do Instituto Ethos 
de Responsabilidade Social das Empresas em 1998.

Segundo Young (2008), o grupo que começou o Instituto Ethos era composto por "Oded [Grajew], Guilherme [Peirão Leal], Helio [Mattar], eu [Young], Sérgio Mindlin, Emerson [Kapaz], Eduardo Capobianco". Enquanto Oded assumiu a presidência do Instituto Ethos, seguido por Ricardo Young, Hélio Mattar assumiu a presidência do Instituto Akatu para o consumo consciente; Eduardo Capobianco assumiu a presidência da Transparência Brasil, organização não governamental fundada para combater a corrupção.

Segundo Young (2008), o grupo que fundou o Instituto Ethos pertenceu ao PNBE e todos os seus membros estavam ligados à fundação Abrinq. Em sua maioria, os fundadores do Instituto Ethos passaram pela Fundação Getúlio Vargas e vieram do PNBE. A trajetória desses agentes revela a convergência existente entre essas organizações não governamentais, as quais, à primeira vista, parecem distintas, mas foram criadas a partir de um mesmo grupo geracional de atores sociais. Segundo Gomes (2007, p. 170), o "desenvolvimento da RSE no Brasil foi um desdobramento de uma nova orientação política de um setor do empresariado, que incorporou 'exemplos práticos' de intervenção social como parte de sua atuação política, nos final dos anos $80 "$. Portanto, pode-se inferir que esse grupo se caracteriza por incluir executivos atuantes na década de 90, ligados à FIESP, ao PNBE e à Fundação Abrinq, com circulação internacional, e que passaram a atuar no terceiro setor, criando suas próprias instituições e distinguindo-se dos empresários industriais tradicionais.

A criação do Instituto Ethos pode ser considerada uma das evidências do surgimento de um novo tipo de empresário que, para distinguir-se do empresariado industrial tradicional, criou uma nova maneira de pensar associada ao empreendedorismo (pois muitos eram ligados a pequenas e médias empresas) e à participação ativa do empresariado brasileiro em questões sociais. A partir dessa diferenciação, esses atores viabilizaram sua inserção como empresários na sociedade brasileira.
O discurso escolhido por esse novo empresariado demonstrou ser profícuo e constituiu uma nova polarização entre os empresários: a do empresariado socialmente responsável versus o empresário tradicional, sem preocupações sociais. Mais ainda: surge uma primeira distinção geracional entre os empresários com foco na ética dos negócios e (ou) direcionados por crenças religiosas (década de 60/70) versus esses novos entrantes, que pensavam na atuação social do empresário de maneira mais política, ampla e sistemática.

\section{RESPONSABILIDADE SOCIAL EMPRESARIAL VERSUSSUSTENTABILIDADE EMPRESARIAL}

O conceito de desenvolvimento sustentável se difundiu por meio da United Nations Conference on Environment and Development (UNCED-92). Porém a origem oficial do conceito é comumente atribuída ao relatório divulgado pelas Nações Unidas em 1987, intitulado, Our common future ou Relatório de Brundtland, segundo o qual "a humanidade tem a habilidade de realizar o desenvolvimento sustentável para garantir que ela satisfaça as necessidades do presente sem comprometer a habilidade das gerações futuras de satisfazerem suas próprias necessidades" (World Commission on Environment and Development, 1987, s/p).

A UNCED-92 teve como um de seus desdobramentos a inserção mais explícita dos empresários nas questões do meio ambiente a partir da criação da Fundação Brasileira para o Desenvolvimento Sustentável (FBDS) por Israel Klabin e, no plano internacional, da criação do World Business Council for Sustainable Development (WBCSD). A WBCSD é uma associação global que reúne executivos envolvidos com a sustentabilidade e os negócios e que, em 1997, lançou a sua filial brasileira, o Conselho Empresarial Brasileiro para o Desenvolvimento Sustentável (CEBDS), sob o comando de Fernando Almeida.

As características de seus fundadores convergem para um tipo ideal de empresário localizado 
no Rio de Janeiro: ambos adotam a postura de executivos que operam na esfera pública, ou via participação política - Klabin foi prefeito do Rio de Janeiro em 1979-ou via trabalho acadêmico em agências público-estatais como o fez Fernando Almeida.

Ao analisar as minibiografias dos atores sociais citados até então, é possível observar uma distinção baseada na localização geográfica dos agentes. Por um lado, tanto a FBDS quanto o CEBDS apareciam no Rio de Janeiro, associando as ações sociais do empresariado, principalmente, ao meio ambiente e a uma visão do longo prazo. Por outro, em São Paulo, aparecia a ideia de investimento social privado e de responsabilidade social empresarial, associando as ações sociais dos empresários a uma dimensão estratégica voltada para os públicos interessados.

Paralelamente, enquanto as ideias em torno das práticas sociais dos empresários se institucionalizavam, outra ideia também ganhava forças: a governança corporativa.

O retorno à ideia de Friedman (1970) de que as empresas deveriam prestar contas prioritariamente aos seus acionistas ocorreu a partir da nova conotação atribuída ao termo "governança corporativa", o qual foi criado na forma de práticas para que a relação entre o executivo e o acionista fosse transparente, priorizando os interesses dos acionistas. Essa concepção foi amplamente difundida no Brasil pelo Instituto Brasileiro de Governança Corporativa (IBGC) na segunda metade da década de noventa.

Observa-se, portanto o surgimento de dois movimentos, à primeira vista, paradoxais: enquanto a RSE, representada pelo Instituto Ethos, prega o foco das ações do executivo nos públicos interessados (stakeholders), a governança corporativa, representada pelo Instituto Brasileiro de Governança Corporativa, orienta seu foco nas boas relações das empresas com seus acionistas.

Esse paradoxo é solucionado no âmbito do setor financeiro por meio da progressiva incorporação da dimensão da responsabilidade social empresarial como um dos pilares da governança corporativa. Segundo Sartore (2006), essa união é particularmente bem evidente no setor bancário brasileiro. Para os bancos, incorporar as dimensões sociais e ambientais da empresa junto à sua dimensão financeira passou a significar Sustentabilidade Empresarial (SE).

\section{SUSTENTABILIDADE EMPRESARIAL VERSUS FINANÇAS SUSTENTÁVEIS (INVESTIMENTO SOCIALMENTE RESPONSÁVEL)}

O início do século XXI apresenta a construção de uma nova distinção cognitiva devido à incorporação das práticas de SE pelo setor financeiro. Essa nova distinção cria duas novas polaridades entre a responsabilidade social das empresas, gerada pelos empresários paulistas, e o Investimento Socialmente Responsável (ISR) concebido pelos investidores e gestores de fundos de investimentos, os quais buscam, através de inovações financeiras, situar a profissão que exercem no campo financeiro.

No Brasil, a difusão do mercado do ISR está intrinsecamente relacionada à objetivação da SE no índice de sustentabilidade empresarial (ISE), na Bolsa de Valores do Estado de São Paulo. O ISE reúne, em sua carteira de investimentos, empresas consideradas socialmente responsáveis e representa, portanto, a atribuição de valor à sustentabilidade pelo mercado financeiro.

Assim, para compreender quem foram os agentes de criação do mercado ISR, é necessário olhar para os agentes sociais que constituíram o ISE mais detalhadamente.

\section{ABN AMRO Real}

O primeiro fundo socialmente responsável lançado no Brasil surgiu como resultado do processo de concentração bancária no final dos anos noventa. A aquisição do Banco Real pelo Banco ABN AMRO gerou uma série de estratégias para criar uma nova imagem do banco associada às ideias de preservação do meio ambiente e da sociedade. 
Um de seus resultados consistiu na criação do fundo Ethical do então Banco ABN AMRO Real ${ }^{2}$ em 2001 (Fundos..., 2006).

Os profissionais ligados ao Banco ABN AMRO REAL têm, em sua maioria, formação em negócios, pertencem a uma geração de profissionais atuantes no mundo das finanças através do setor bancário e possuem estudo ou experiência profissional no exterior.

Fábio Barbosa, particularmente, construiu a imagem do "Banqueiro Verde" (Prado; e Rosenburg, 2007) ao inserir as ideias de sustentabilidade empresarial na estratégia do Banco ABN AMRO REAL. A figura de Fábio Barbosa é emblemática, pois não apenas criou um nicho de atuação dos dirigentes dos bancos a partir da ótica da SE, como a expandiu como um diferencial de gestão e de atuação política dos bancos.

A expressiva presença de executivos do ABN AMRO REAL em diretorias de entidades de representação de classe, como a Federação Brasileira dos Bancos (FEBRABAN) ou ainda no Banco Central (Minella, 2009) pode ter contribuído para a expansão das ideias de SE no mercado financeiro. Não é por acaso que, em 2002, a FEBRABAN criou uma Comissão de Responsabilidade Social e Sustentabilidade, iniciando o ciclo "café com sustentabilidade” em 2007 e, por fim, em 2009, realizou o Seminário FEBRABAN de Finanças Sustentáveis.

Ainda não é por acaso que a crescente realização de eventos que discutem finanças e sustentabilidade tenha ocorrido a partir do ano de 2007, quando Fábio Barbosa assumiu a diretoria executiva da FEBRABAN.

Junto a Fábio Barbosa, o personagem de Luiz Eduardo Passos Maia é relevante para se compreender a emergência dos investimentos socialmente responsáveis no Brasil. Luiz Eduardo Passos Maia trabalhou no Banco ABN AMRO REAL na implementação do Fundo Ethical e, posteriormen-

2 O Banco ABN AMRO REAL foi comprado em 2008 pelo Banco SANTANDER. Porém, como os desdobramentos de nossa história ocorreram quando o banco era chamado BANCO ABN AMRO REAL, será assim referido ao longo do texto. te, em 2003, procurou a Bovespa, ${ }^{3}$ com o intuito de desenvolver um índice para servir de parâmetro ao Fundo Ethical. Para tal tarefa, requisitou a parceria do Instituto Ethos e do Instituto Brasileiro de Governança Corporativa.

Luiz Eduardo Passos Maia é um dos diretores executivos da Associação Nacional dos Bancos de Investimento (ANBID) e foi seu primeiro representante no grupo que forma o Conselho do Índice de Sustentabilidade Empresarial. Possui ampla circulação no espaço internacional, pois trabalhou em bancos comerciais no exterior. Essa circulação pelo espaço internacional lhe rendeu o aumento de seu capital social, evidenciado pela participação como palestrante em fóruns nacionais (Fórum do Investidor e Seminário FEBRABAN de Finanças Sustentáveis) e internacionais sobre o tema (Triple Bottom Line Investing Conference, Fórum de Lideres em Sustentabilidade). Dessa maneira, tanto Fábio Barbosa quanto Luiz Eduardo Passos Maia apresentam um novo perfil profissional no espaço das finanças: o perfil do financista preocupado com o meio ambiente, o lucro e a sociedade e que ocupa cargos de diretoria em associações de representação de interesses de classe a que eles pertencem, com alta circulação na esfera dos negócios financeiros internacionais.

Existem mais dois protagonistas desse processo: Luiz Ribeiro e Pedro Angeli Villani. Ambos construíram carreira no Banco ABN AMRO REAL e também circulam em conferências internacionais sobre investimento socialmente responsável. Luiz Ribeiro passou a atuar no International Finance Corporation (IFC), enquanto Pedro Angeli Villani manteve a sua carreira no Banco ABN AMROREAL. Ambos também possuem uma atuação profissional vinculada ao setor bancário associada a uma circulação no plano internacional das finanças.

Informação obtida em entrevista realizada com Luiz Eduardo Passos Maia em dezembro de 2008, na ocasião da realização do Fórum do Investidor Responsável do programa New Ventures. O entrevistado não autorizou a gravação da entrevista, que ocorreu na forma de anotações em bloco de notas. 


\section{Academia e Terceiro Setor}

O grupo de analistas de investimentos do Banco ABN AMRO REAL, particularmente por meio da figura de Luiz Eduardo Passos Maia, convergiu com atores ligados ao setor acadêmico e ao terceiro setor. No ano de 2000, a Organização da Sociedade Civil de Interesse Público (OSCIP) Amigos da Terra lançou o programa Eco-Finanças (2012), que visa a monitorar e assegurar que os investimentos e financiamentos das instituições financeiras estejam dentro dos padrões da sustentabilidade. Uma das atividades do projeto consistiu no treinamento de mais de 1500 funcionários do Banco ABN AMRO Real em 2002 (Mano, 2007). Esse treinamento é emblemático, pois apresenta uma convergência entre uma organização não governamental (Eco-finanças, 2012), liderada por atores sociais atuantes na Fundação Getúlio Vargas (EAESP), e foi aplicado em um banco comercial privado (ABN AMRO Real). Esse encontro permitiu a criação de um espaço de convergência entre os líderes do Banco ABN AMRO REAL que vinham desenvolvendo projetos na área da Sustentabilidade com líderes interessados em criar e monitorar essas práticas a partir da área acadêmica e do terceiro setor.

A Fundação Getúlio Vargas já estava atuando em estudos sobre a ética nos negócios através da criação do Centro de Estudos de Ética nas Organizações (CENE) em 1997. Esse centro cooperava com a FIDES. Dentre os projetos do CES, encontramos o desenvolvimento da metodologia para a elaboração da carteira teórica do Índice de Sustentabilidade Empresarial (ISE) da Bovespa.

A participação do CES no ISE é por eles entendida como uma atividade dentro de um campo maior, que o instituto denomina "finanças sustentáveis", o qual não apenas diria respeito aos investimentos financeiros, mas também "à atuação do sistema financeiro de forma economicamente viável, socialmente justa e ambientalmente correta." (CES, 2010). Assim, finanças sustentáveis procura englobar todas as atividades desenvolvidas pelo setor financeiro para alcançar a sustentabilidade tanto na questão do investimento como na concessão de crédito e inclusão bancária. Para consolidar essa ideia, o CES, convergindo com o Internacional Finance Corporation (IFC) e com o apoio da FEBRABAN, lançou, em 2005, o Fórum Latino Sobre Finanças Sustentáveis (LASFF), com o intuito de promover as finanças sustentáveis na América Latina.

A partir dos desdobramentos das estratégias da convergência desses agentes, é possível identificar a criação da nova polarização que é traduzida pela Responsabilidade Social Empresarial, de um lado, e pelo seu desdobramento em Investimento Socialmente Responsável, de outro. Vale ressaltar que tanto o mundo empresarial da responsabilidade social das empresas quanto o mundo financeiro das finanças sustentáveis defendem o mesmo ponto de vista, mas o fazem com vocabulários específicos de seu campo de atuação, criando um efeito de teoria (Bourdieu, 1982), no qual, ao se criarem distinções na linguagem, novas realidades, subsequentemente, são criadas.

Assim, o CES, em parceria com o Banco ABN AMRO REAL e com o ECO-FINANÇAS, cria uma nova linguagem, associada às finanças sustentáveis, vinculada a novas ferramentas de análise para definir o que é ser financeiramente sustentável ou não. Ao fazê-lo, cria e legitima um mercado próprio de atuação. A militância do CES pela difusão do ISR fica explícita na fala de Monzoni (2008) em palestra, quando afirma que a "Sustentabilidade será o mainstream - não haverá outra possibilidade de investimento que não incorpore questões de governança, sociais e ambientais.".

$\mathrm{Na}$ França, o mercado do Investimento Socialmente Responsável ganhou impulso a partir da criação de uma agência de notação social chamada Agence de Rating Environnemental et Social des Entreprises (ARESE) em 1997, ou seja, a partir da existência de um grupo reconhecido como expert na temática em atribuir notas para as empresas sustentáveis (Loiselet, 2003). O CES da Fundação Getúlio Vargas ocuparia no Brasil uma posição análoga à ARESE no começo do mercado ISR na França, pois consiste no único grupo de profis- 
sionais que não atua no mercado financeiro a disponibilizar este tipo de serviço de notação social a partir da elaboração da metodologia do Índice de Sustentabilidade Empresarial.

O grupo que formou o CES constitui uma primeira geração de profissionais formados na área de negócios, que também atuaram no terceiro setor. Esse grupo, que atuou no treinamento dos gerentes do ABN AMRO Real, era constituído do então seu coordenador, Mário Monzoni, e a então responsável pela comunicação do projeto, Gladis Ribeiro. Se esses primeiros atores foram relevantes para a criação das ideias associadas ao ISR, já é possível observar o desdobramento dessa atuação no aparecimento de uma segunda geração de atores que circularam pelo projeto Eco-Finanças e criaram a consultoria "Finanças Sustentáveis". Seus idealizadores, Cássio Trunkl e Victorio Mattarozzi, são ex-bancários com circulação internacional. Ambos realizaram a elaboração dos critérios socioambientais do Índice de Sustentabilidade, em suas versões de 2005 e 2006.

Assim, os desenvolvimentos institucionais na área da sustentabilidade e das finanças, no começo do século XXI, abriram o espaço para que profissionais da área de negócios com passagem pelo terceiro setor, ou seja, por organizações não governamentais, encontrassem um nicho de atuação: enquanto o primeiro grupo buscou a consagração pela esfera acadêmica, o segundo buscou a consagração na esfera do conselho especializado a partir da criação de uma consultoria. Ambos os grupos têm uma ligação com o índice de sustentabilidade empresarial, reforçando a hipótese de que uma passagem pela esfera do ISE torna o profissional legítimo para a atuação no âmbito das finanças sustentáveis e mais particularmente, no âmbito do investimento socialmente responsável no Brasil.

\section{Influência internacional}

A iniciativa financeira do Programa das Nações Unidas para o Meio Ambiente (UNEP-FI) foi lançada em 1991 pelas Nações Unidas em parceria com bancos comerciais. A UNEP-FI tem uma dupla importância para o desenvolvimento do investimento socialmente responsável, na medida em que desenvolve debates internacionais sobre o tema, ao mesmo tempo em que possui um Grupo de Trabalho, em parceria com o International Finance Corporation, braço privado do Banco Mundial, com atuação direcionada ao desenvolvimento do sistema financeiro em mercados emergentes.

Ao se analisarem as temáticas das conferências da UNEP-FI a partir de 1994, é possível observar claramente suas transformações: inicialmente, o foco era as relações do setor financeiro com o meio ambiente; em seguida, as conferências incorporaram o termo "sustentabilidade" e, por fim, inseriram a temática "investimentos" a qual incorpora o investimento socialmente responsável.

A UNEP-FI possui uma área de atuação chamada "Investimentos". Dentre as diversas atividades desenvolvidas pela linha de Investimentos da iniciativa financeira, uma nos é de particular interesse: o projeto "Investimento Responsável em Mercados Emergentes" (Emerging Market Responsible Investing), iniciado em 2004 com a colaboração com o International Finance Corporation (IFC) e com o suporte financeiro do Ministério de Relações Internacionais da Holanda e da Agência de Desenvolvimento Internacional da Suécia.

O International Finance Corporation participa desse projeto por meio de seu programa inicialmente chamado Sustainable Financial Markets Facility, que atualmente se subdivide em dois programas: o Programa de Investimento Sustentável (Sustainable Investing Program) e a Sustentabilidade nos Mercados Financeiros (Financial Markets Sustainability).

O programa de Investimentos Sustentáveis atua através de instituições financeiras internacionais para promover o desenvolvimento das finanças sustentáveis em mercados emergentes. Esse programa foi o financiador do Índice de Sustentabilidade Empresarial da Bovespa lançado em 2005 (Camba; Fariello; Pavini, 2005). O IFC 
financiou o indicador com um primeiro investimento de U\$ 85.000,00 com trabalho de consultoria para o desenvolvimento da metodologia do índice. Em janeiro de 2007, foi aprovado mais um investimento de U\$120.000,00 (Manasseh, 2007).

Para englobar grandes investidores institucionais, como os fundos de pensão, o programa das Nações Unidas chamado Pacto Global, junto à UNEP-FI, lançaram, em 2006, os Princípios para o Investimento Responsável (PRI). No entanto, já em 2003, havia no Brasil uma iniciativa do Instituto Ethos junto à Associação Brasileira dos Fundos de Pensão (ABRAPP) para lançarem os princípios básicos de responsabilidade social, os quais fariam parte de uma cartilha para o investimento socialmente responsável.

OPRI tem como base a incorporação da ideia por parte dos investidores institucionais de que investir com critérios de governança, sociais e ambientais pode afetar positivamente o desempenho das carteiras de investimento. Assim, a proposta é a de criação de um referencial para que os investidores possam incorporar essas práticas ao seu dever de gerir recursos de terceiros.

Segundo Rebouças (2006), a caixa de previdência dos funcionários do banco do Brasil (PREVI), junto ao Fundo de Pensão da Tailândia, foram os únicos dois grupos do terceiro mundo convidados para participar da elaboração destes princípios.

Esse posicionamento dos Fundos de Pensão pode ser atribuído ao que Jardim (2009) demonstra em seu trabalho que sobre a financeirização dos fundos de pensão brasileiros sob a direção de uma "elite sindical". Esse grupo, para se diferenciar de seus antecessores, estaria mais disposto a aderir à filosofia do ISR. Os fundos de pensão brasileiros ganham cada vez mais destaque no cenário econômico-financeiro, como evidencia a edição de fevereiro do Valor Investe, ao chamar os fundos de pensão de "Novas Estrelas da Bolsa"(As Estrelas..., 2010). ${ }^{4}$ Assim, Monzoni, entrevistado por Mattos (2007), afirma que, "com o poder eco-

${ }^{4}$ A revista evidencia a crescente participação dos fundos de pensão no financiamento de empresas de infraestrutura no Brasil. nômico desses fundos, mesmo que entrem discretamente no mercado, já fará uma bela diferença”. Dessa forma, os agentes ligados ao ISR acreditam que a adesão dos fundos de pensão às práticas do ISR é fundamental para o sucesso desse mercado em escala nacional e mundial.

\section{CONSIDERAÇÕES FINAIS SOBRE A (RE) CONSTITUIÇÃO DO ESPAÇO DAS PRÁTICAS SOCIAIS: da filantropia ao investimento socialmente responsável}

O presente artigo apresentou uma cronologia a partir de instituições e atores sociais relevantes para a compreensão do espaço das práticas sociais dos empresários.

As distinções que foram criadas na evolução histórica das práticas sociais dos empresários situam os indivíduos em quatro polos distintos, como é ilustrado na Figura 1: ao norte, os executivos de gerações empresariais das décadas de 60/ 70 e 80, ligados ao tradicionalismo, à filantropia e às ações mais nacionais (pois não têm ampla circulação internacional. No polo oposto, ao sul, os executivos da década de 90 e início do século XXI, a vanguarda, ligados ao meio ambiente e com alta circulação internacional. À direita, os indivíduos ligados ao mundo das finanças sustentáveis e ao investimento socialmente responsável versus, à esquerda, os indivíduos ligados ao mundo das empresas, da RSE e do desenvolvimento sustentável.

Vale ressaltar que essa reconstituição não apenas "tira uma fotografia" do espaço das práticas sociais do empresário como demonstra a sua evolução histórica e geracional. Mesmo não sendo possível mapear o ano de nascimento de todos os atores sociais envolvidos, é possível inferir que a evolução das diferentes conotações atribuídas às práticas sociais dos empresários pode ser vista pelo viés da sociologia das gerações.

Karl Mannheim (1928) argumenta em prol do potencial explicativo e analítico das gerações vistas como grupos formados a partir de uma mesma idade cronológica, que compartilham de uma 
Figura 1 - O espaço dos atores das práticas sociais dos empresários e suas polarizaçóes

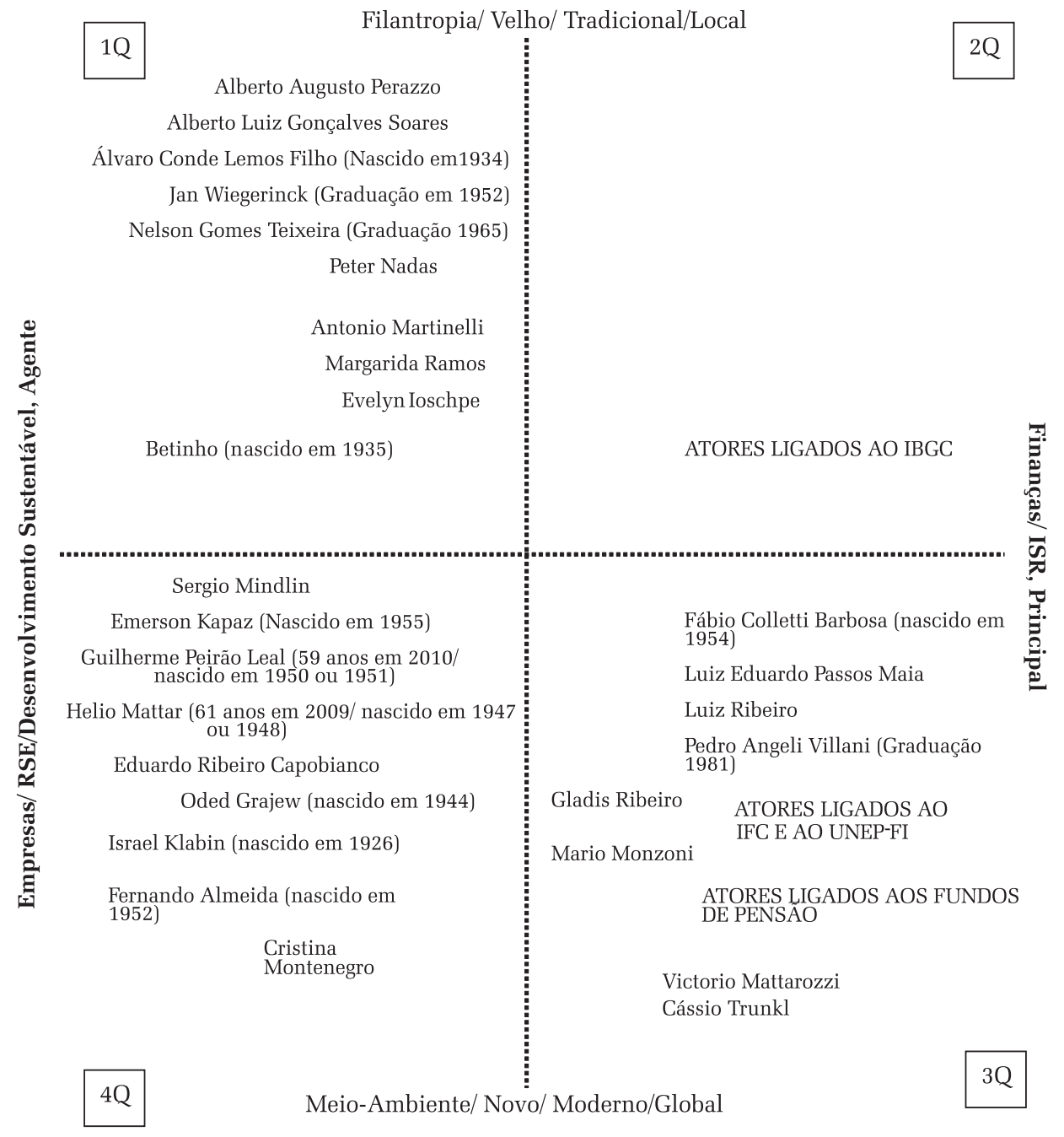

mesma unidade histórico-social e possuem motivações similares. Nesse sentido, os dados analisados convergem com a ideia de Mannheim (1928), pois, apesar de não ser extremamente conclusivo, tudo se passa como se o pertencimento a um determinado período histórico e a uma determinada geração de empresários com motivações comuns possa ser considerado um dos fatores determinantes para as diferentes concepções sobre as práticas sociais dos empresários apresentadas neste artigo.

No primeiro quadrante, situamos os protagonistas que pertencem ao primeiro momento (Filantropia Empresarial), ou seja, atores ligados à FIDES, ao IBASE e ao GIFE. No segundo e no quar- to quadrante, situamos os protagonistas que pertencem ao segundo e terceiro momento respectivamente (Responsabilidade Social Empresarial, Desenvolvimento Sustentável e Sustentabilidade Empresarial). E, por fim, no terceiro quadrante, situamos os protagonistas do Investimento Socialmente Responsável.

Essas oposições demonstram que a tomada de posição no espaço da responsabilidade social empresarial depende muito menos da área de formação acadêmica, pois todos são, em sua maioria, formados na área de negócios, do que pela sua trajetória profissional, idade e instituições pelas quais passaram. Demonstra também que se trata muito menos de um espaço de práticas divergen- 
tes do que de um espaço homogêneo para a convergência de novas elites empresariais.

Também é possível observar uma polarização entre, de um lado, os atores ligados à esfera da responsabilidade social empresarial e do desenvolvimento sustentável, e, de outro, atores ligados às finanças e à governança corporativa. A principal distinção é a de que os primeiros focam as suas práticas para os executivos das empresas, enquanto os segundos focam as suas práticas para os investidores.

A incorporação da Sustentabilidade Empresarial pelo mundo das finanças recria, por exemplo, as distinções existentes entre a categoria de proprietário/acionista/investidor e a do gerente: de um lado, há executivos que desenvolvem ações "sustentáveis" baseados nas diretrizes do Instituto Ethos; de outro, os acionistas e ou investidores que reconstroem a sua própria noção do que significa ser "sustentável".

Trata-se, portanto, de uma recolocação do clássico problema da agência. Assim, de um lado, há o executivo de uma empresa buscando implementar as práticas de responsabilidade social no dia a dia da empresa, ao mesmo tempo em que deve atender às diferentes exigências de sustentabilidade para a criação de valor para o acionista. Este dilema fica evidente no caso do crescente número de questionários que são submetidos às empresas nos últimos anos como por exemplo, os indicadores Ethos, o questionário do Índice de Sustentabilidade Empresarial, os indicadores do Fundo Ethical, etc. São diferentes instituições utilizando os seus critérios específicos para avaliar a Sustentabilidade de uma empresa. Estes questionários acabam por definir quais são as pautas prioritárias no que concerne a Sustentabilidade Empresarial para o dia-a-dia das empresas.

Essa relação recoloca em questão quem é que "dita" as regras sobre o que gera valor para a empresa em termos de sustentabilidade empresarial. São os agentes que fomentaram o movimento da responsabilidade social empresarial na década de 90, ou as instituições ligadas ao mercado financeiro?

Esta questão ainda não possui uma respos- ta. O que é possível identificar é a existência de distinções no espaço das práticas sociais do empresário brasileiro a partir da incorporação destas práticas pelo espaço das finanças. A incorporação destas práticas é resultado de uma convergência de elites associadas ao mercado financeiro, ao terceiro setor, ao espaço acadêmico e até mesmo ao espaço sindical. Uma evidência da distinção semântica que se forma é a adoção de termos distintos como People, Planet and Profit (PPP) versus Environment, Social and Governance (ESG) que, na prática, são a mesma coisa. A tríade PPP é representada pelos que advogam em prol da Responsabilidade Social Empresarial por meio da ideia de Triple Bottom Line cunhada por John Elkington da consultoria SustainAbility a partir da qual a empresa deve atuar em prol das People (Pessoas), Profit (Lucro) e Planet (Planeta) (Elkington, 2004). No entanto, no espaço das finanças, esta tríade é substituída pela Environment, Society and Governance - $E S G^{5}$ Esta distinção entre duas siglas que à primeira vista querem dizer a mesma coisa demonstra uma nova estruturação da percepção subjetiva do mundo das finanças através da linguagem que é "o produto das lutas simbólicas anteriores e exprime, de forma mais ou menos transformada, o estado das relações de forças simbólicas" (Bourdieu, 1994, p. 139).

Desse modo, é possível afirmar que, principalmente a partir da incorporação da sustentabilidade pelo mercado financeiro, estamos diante de uma reconfiguração no espaço das práticas sociais dos empresários por meio do aparecimento de novos atores e novas formas de expressão que tornam mais claras as disputas no espaço das suas práticas sociais.

(Recebido para publicação em 20 de dezembro de 2011) (Aceito em 27 de abril de 2012)

\footnotetext{
${ }^{5}$ Para maiores detalhes ver por exemplo, o relatório lançado pelo International Finance Corporation em parceria com o grupo Mercer "Gaining ground: integrating environmental, social and governance (ESG) factors into
} investment processes in emerging markets" Março 2009. 


\section{REFERÊNCIAS}

AGÜERO, Felipe. Business, politics and the surge of corporate social responsibility in Latin America. Antropolítica, Niteói, n. 18, p. 57-76, 2005. Disponível em http://www.uff.br/antropolitica/revistasantropoliticas revista_antropolitica_18.pdf. Acesso em: 21 dez. 2012.

ASSIS, Jaime S. de. PNBE chega à maioridade com perfil discreto e novas bandeiras. Gazeta Mercantil, 3 de jul. 2008. Disponível em: http://www2.senado.gov.br/bdsf/ item/id/147749. Acesso em: 21 dez. 2012.

BEGHIN, Nathalie. A filantropia empresarial: nem caridade, nem direito. São Paulo: Cortez, 2005.

BIANCHI, Alvaro. Crise e representação empresarial: o surgimento do pensamento nacional das bases empresariais. Rev.Sociol. Polít., Curitiba, n. 16, p. 123-142, jun. 2001. Disponível em: http://www.scielo.br/pdf/rsocp/n16/ a08n16.pdf. Acesso em: 21 dez. 2012.

BOURDIEU, Pierre. Espace social et genèse des 'classes' Actes de La Recherche en Sciences Sociales, Paris, v. 52, n. 52-53, p. 3-15, 1984. Disponível em: www.persee.fr/web/ revues/home/prescript/article/arss_0335 5322_1984_num_52_1_3327. Acesso em: 21 dez. 2012. BOURDIEU, Pierre. Ce que parler veut dire: l'économie des échanges linguistiques. Paris: Fayard, 1982. p. 149-161. sil, 1994

O poder simbólico. Rio de Janeiro: Bertrand Bra-

WORLD COMMISSION ON ENVIRONMENT AND DEVELOPMENT. Our common future: the world commission on environment and development. Oxford Oxford University Press, 1987.

CAMBA, D; FARIELLO, D; PAVINI, A. ISE nasce para o investidor que quer muito mais do que o lucro. Jornal Valor Econômico, São Paulo, $2 \mathrm{dez}$. 2005. Disponível em www.valoronline.com.br/valoreconomico/285 eueinvestimento/49/ISE + nasce + para + investidor + que+quer+muito+mais +que+o+lucro,,,49,3412290.html. Acesso em: 28 nov. 2006

CAPPELLIN, P; GIULIANI, G. M. The Political Economy of Corporate Responsibility in Brazil: Social and Environmental Dimensions. In: UNITED NATIONS RESEARCH INSTITUTE FOR SOCIAL DEVELOPMENT (UNRISD). Tecnology, Business and Society. Genebra: UNRISD, 2004. v. 14, p. 1-67.

( CARRION, R. S. M; GARAY, A. Organizações Privadas ๑ Sem Fins Lucrativos: a participação do mercado no terceiro setor. Tempo Soc., São Paulo, v. 12, n. 2, p. 237-255, \& nov., 2000.Disponível em: http://www.scielo.br/pdf/ts/ fi v12n2/v12n2a15.pdf. Acesso em: 21 dez. 2012.

CASTEL, Robert. As metamorfoses da questão social: uma crônica do salário. Rio de Janeiro. Petrópolis, 1998.

CES. Finanças Sustentáveis. Disponível em: http:// ces.fgvsp.br/gvces/index.php?page=Conteudo\&id $=25$ Acesso em: 21 out. 2010.

DINIZ, Eli; BOSCHI, Renato. Lideranças empresariais e problemas da estratégia liberal no Brasil. Revista Brasileira de $\therefore$ Ciências Sociais, Rio de Janeiro, v. 8, n. 23, p. 101-119, 1993. HENRIQUES, Adrian; RICHARDSON, Julie (Org.). The triple bottom line: does it all add up? Routledge: Londres, 2004 Acesso em: Disponível em: www.johnelkington.com/TBLelkington-chapter.pdf. Acesso em: 21 dez. 2012.

ECO-FINANÇAS. Apresentação. Disponível em: http:// ef.amazonia.org.br/?fuseaction = guiaDetalhes\&id = $223366 \&$ tipo $=6 \&$ cat $i d=157 \&$ subcat $i d=549$. Acesso em: 21 dez. 2012.
FIDES. O que é. 2010. .Disponível em: www.fides.org.br/ apresentacao_oquee.htm. Acesso em: 27 jan. 2010.

FIDES. Apresentação Curadoria. 2010b. Disponível em: www.fides.org.br/apresentacao curadoria.htm\#um. Acesso em: 27 jan. 2010.

FRIEDMAN, Milton. The social responsibility of business is to increase its profits. The New York Times Magazine. New York, 13 set. 1970. Disponível em: http:// www.colorado.edu/studentgroups/libertarians/issues/ friedman-soc-resp-business.html. Acesso em: $21 \mathrm{dez}$. 2012.

GOMES, E. Além do mercado: origens, características e trajetória da responsabilidade social das empresas no Brasil. In: GOMES, Angela (Org.). Direitos e cidadania: justiça, poder e mídia. Rio de Janeiro: FGV, 2007.

GRÜN, Roberto. Financeirização de esquerda? frutos inesperados no Brasil do século XXI. Tempo Soc., São Paulo, v. 21, n. 2, p. 153-184, 2009. Disponível em: http:// www.scielo.br/pdf/ts/v21n2/v21n2a08.pdf. Acesso em: 21 dez. 2012.

GUILHOT, Nicolas. Financiers, philanthropes sociologie de Wall Street. Paris: Raisons D’Agir, 2006.

GIFE. São Paulo, 2009. Disponível em: http:// www.gife.org.br/ Acesso em: 21 dez. 2012.

IBASE Informação 2010. Disponível em: http:// www.ibase.br/modules.php?name $=$ Conteudo\&pid $=40$. Acesso em: 27 Jan. 2010.

JARDIM, Maria A. Entre a solidariedade e o risco: sindicatos e fundos de pensão em tempos de governo Lula. São Paulo. Annablume, FAPESP, 2009.

LOISELET, Eric. Investissement socialement responsable: l'âge de la diffusion. L'économie politique, Paris, v. 2 n. 18, p. 62-74, abr., 2003.

MANASSEH, K. IFC promotes sustainability in Brazil. 2007. Disponível em: http://www.ifc.org/ifcext/media.nsf/ Content/Brazil_Sustainability_Index_Jun07. Acesso em: 17 jun. 2007

MANNHEIM, Karl . Sociologia do conhecimento. Porto, RES, [1928]. v. 2. p. 115-176.

MANO, Cristiane. Negócio sustentável: a corrida por uma imagem sustentável. Revista Exame, São Paulo, 9 maio 2007. Disponível em: http://planetasustentavel.abril.com.br/noticia/desenvolvimento/conteudo_232184.shtml. Acesso em: 19 dez. 2012.

MATTOS, A. Gestão para o futuro. Jornal Valor Econômico, São Paulo, 2010.

MINELLA, A. C. Bancos e banqueiros no Brasil: uma análise sociopolítica. In: MONDADORE, A. P.C et al. (Org.) Sociologia Econômica e das Finanças: um projeto em construção. São Carlos: Editora da Unniversidade Federal de São Carlos, 2009. p. 275-297.

MONZONI, M. Palestra. Fórum dos Investidores. 2008. In: ENCONTRO DE FÓRUM DE INVESTIDORES SOCIAIS (FIS), 3., 2008, Belo Horizonte.

NOGUEIRA, Ricardo. Índice de Sustentabilidade Empresarial (ISE) [São Paulo: BOVESP], 2005. Disponível em: www.ces.fgvsp.br/ arquivos/conferencia_internacional_p7\%20bovespa.pdf. Acesso em: 21 dez. 2012.

PRADO, Alberto; ROSENBURG, Cynthia. O Banqueiro verde. Época Negócios, São Paulo, 26 jul., 2007. Disponível em: http://epocanegocios.globo.com/Revista/ Epocanegocios/0,,EDG76599-8379-1,00.html. Acesso em: 21 dez. 2012.

REBOUÇAS, L. Previ participa do Global Compact. Suplemento Especial Gazeta Mercantil, São Paulo, 9 out. 2006. p. 2. 
FUNDOS do ABN e do Itaú foram os precursores. Jornal Valor Econômico, São Paulo, 13 mar. 2006. Disponível em: www.valoronline.com.br/valoreconomico/285/financas/54/ Fundos+do+ABN+e+do+Itau+foram++ precursores,,,54,3576567.html. Acesso em: 28 nov. 2006

SARTORE, Marina S. A inserção da responsabilidade social do setor bancário no contexto da governança corporativa. 2006. 91f. Dissertação (Mestrado em Engenharia de Produção) - Centro de Ciências exatas e Tecnologia, Universidade Federal de São Carlos, São Carlos, 2006.

. Convergência de elites: a sustentabilidade no mercado financeiro. 2010. 207f. Tese (Doutorado em Ciências Sociais) - Centro de Educacão e Ciências, Universidade Federal de São Carlos, São Carlos, 2010.
YOUNG, Ricardo. Entrevista. 2008. Disponível em: www.consumidormoderno.com.br/canais/responsabilidade-social/responsabilidade-social-1/entrevista-comricardo-young-parte-1. Acesso em: 08 fev. 2009.

AS ESTRELAS da bolsa. Valor Investe, São Paulo, v. 7, n. 36, fev. 2010.

INTERNATIONAL FINANCE CORPORATION; MERCER. Gaining ground: integrating environmental, social and governance (ESG) factors into investment processes in emerging markets. Washington, 2009.

MAIA, Luiz Eduardo P.; BARBOSA, Fábio. [Entrevista no fórum do investido]: depoimento. [mar. 2008]. Entrevistadores: Marina de Souza Sartore. LOCAL: 2008. 


\section{FROM PHILANTHROPY TO SOCIALLY RESPONSIBLE INVESTMENT: new distinctions}

\author{
Marina de Souza Sartore
}

The transformations in the organizational and financial world are creating oppositions which define the positions of the actors in the social arena, which I call "Corporate Social Practices Arena.” My main argument is that these recent transformations have become more evident with the incorporation of the ideas of Corporate Sustainability by actors in the field of finance, which has occurred since the creation of the Business Sustainability Index (ISE) in the São Paulo State Stock Market in 2005. I conclude this article by presenting a map of this social space made up of the polarization between philanthropy, the old, the traditional, the local versus the environment, the new, the modern and the global; or also, on one hand finance and socially responsible investment, and on the other, social responsibility of companies and company sustainability.

KEY wORDS: Social arena. Company responsibility. Social responsibility of companies. Economic sociology.

\section{DE LA PHILANTROPIE A L'INVESTISSEMENT SOCIALEMENT RESPONSABLE: de nouvelles distinctions}

\author{
Marina de Souza Sartore
}

Les transformations du monde de la finance et de l'organisation engendrent des oppositions qui définissent les postures des acteurs qui agissent dans l'espace social et que je désigne sous le nom de "Espaces des Pratiques Sociales des Entrepreneurs". L'argument principal avancé est que ces changements récents deviennent de plus en plus évidents avec l'incorporation de l'idée de Durabilité des Entreprises (DE) par des acteurs appartenant au domaine des finances et qui date de la création, en 2005, d'un Indice de Durabilité des Entreprises côté en Bourse de l'Etat de Sao Paulo. Pour conclure, l'article présente la cartographie de cet espace social formé à partir de polarisations entre la philanthropie, l'ancien, le traditionnel, le local versus l'environnement, le nouveau, le moderne et le global ou encore les finances d'un côté et l'investissement socialement responsable versus la responsabilité sociale et la durabilité des entreprises.

Mots-ClÉs: Espace social. Durabilité entrepreneuriale. Responsabilité sociale entrepreneuriale. Investissement socialement responsable. Sociologie économique.

Marina de Souza Sartore - Doutora em Ciências Sociais pela Universidade Federal de São Carlos. Professora da Faculdade de Ciências Sociais da Universidade Federal de Goiás. Integra o Programa de Pós-Graduação em Ciência Política da Universidade Federal de Goiás desenvolvendo pesquisas na área de investimento, Estado e sustentabilidade. Sua mais recente publicação: O mercado socialmente responsável. Revista Espaço de Diálogo e Desconexão. v. 4, 2012. 